\title{
ORAL HEALTH STATUS AMONG ATHLETES IN JAIPUR, RAJASTHAN - A DESCRIPTIVE STUDY
}

\author{
Himani ${ }^{1}$, Naganandini. S ${ }^{2}$, Amit Mahuli ${ }^{3}$, Roma Yadav ${ }^{4}$, Kavita Manchanda ${ }^{5}$, Poonam Jangid ${ }^{6}$ \\ ${ }^{1}$ PG Student, NIMS Dental College, Jaipur, India \\ ${ }^{2}$ Prof \& HOD, NIMS Dental College, Jaipur, India \\ ${ }^{3}$ Reader, NIMS Dental College, Jaipur, India \\ ${ }^{4}$ Sr. Lecturer, NIMS Dental College, Jaipur, India \\ ${ }^{5}$ Reader, Awadh Dental College and Hospital, Jharkhand, India \\ ${ }^{6}$ PG Students, NIMS Dental College, Jaipur, India
}

Corresponding Author:

Himani Yadav

E-mail:

yadavhimani453@gmail.com

Received: $2^{\text {nd }}$ January 2016

Accepted: $21^{\text {st }}$ March 2016

Online: $2^{\text {nd }}$ May 2016

\begin{abstract}
Introduction Oral health is important both for the well-being and successful elite sporting performance. Athletes are at a greater risk of having dental caries, dental erosion and traumatic dental injuries. So this study was taken up to focus on this issue. Objectives: (i) To assess the prevalence and severity of dental erosion, dental trauma, oral mucosal lesions, dental caries and periodontal status among athletes, using WHO oral health assessment form 2013. (ii) To plan appropriate oral diseases prevention and oral health promotion strategy for athletes. Materials and methods: A cross-sectional study was carried out among athletes in SMS STADIUM Jaipur. Clinical examination of the athletes was carried out with the help of WHO proforma 2013. Results: A total of 300 athletes were included with $217(72.3 \%)$ males and $83(27.66 \%)$ females in the age group of $10-35$ years with a mean age of $22 \pm 5.04$ years. Of the participants, $55.3 \%$ participants reported the use of energy drinks. 50\% reported using chewing gums (sweetened) and $20.6 \%$ reported the use of mouth guard during their activities. Around $70 \%$ of the athletes were having DMFT, out of them $68.66 \%$ had decayed teeth and only $12.66 \%$ had filled teeth. $9.3 \%$ of the athletes had enamel erosion. $8.33 \% \& 8.66 \%$ of athletes were having treated injury and enamel fracture, respectively. Conclusion: Athletes are more prone to dental caries because of less care towards oral hygiene and extensive use of sweetened chewing gums and energy drinks.
\end{abstract}

Keywords: Sports Dentistry, Athletes, Oral Health Status

\section{INTRODUCTION}

Athletics is an exclusive collection of sporting events that involves competitive running, jumping, throwing, and walking. Initially, the term was used to describe athletic contests in general, that is sporting competition based primarily on human physical feats.

Training incorporates strategies which coincide with risk factors for dental caries and erosion. The role of a diseasefree oral cavity for peak performance is often overlooked and oral health may be compromised.

The major carbohydrates used in sports drinks are glucose, fructose, sucrose, and the synthetic polymer maltodextrins, also known as glucose polymers. The use of glucose polymers in sports drinks has increased in recent years as they allow for provision of more carbohydrate without a resultant increase in osmolality. ${ }^{1}$ So the sports drinks ultimately lead to dental caries. ${ }^{2}$

Fractured bones, Muscle injuries, torn cartilage, tendonitis, soft tissue lacerations, contusions, and broken teeth are just some of the injuries associated with sports activities.

As far as we know there are very few studies on oral health status among athletes from other countries and there is 
no known study from India. So the present study has been taken up to focus on this issue.

The aim of the study is to assess the oral health status among athletes in Jaipur while objectives are (1) To assess the oral mucosal lesions, dental caries, periodontal status, severity and prevalence of dental erosion, dental trauma among athletes, using WHO oral health assessment form, 2013. (2) To plan appropriate oral health disease prevention and oral health promotion for athletes.

\section{MATERIALAND METHODS}

A cross-sectional study was conducted to assess the oral health status among athletes in SMS stadium, Jaipur. SMS stadium is the main stadium in Jaipur city where sports such as basketball, cricket, kho-kho, football, table tennis, kabaddi etc. take place. All the athletes who come to the stadium for practice have been included in the study. The study was systematically scheduled to be spread over a period of 3 months.

Ethical clearance for the study was obtained by the institutional ethical committee, NIMS University, Jaipur. Voluntary informed written consent was obtained from the athletes after explanation of the nature of the study.

Inclusion criteria were Athletes between the ages of 10-35 years and all athletes who were trained for the purpose of participation in different competitions. Exclusion criteria were Athletes whose questionnaire was incomplete and athletes who were suffering from systematic illness and acute disease condition.

A questionnaire was used to record the athletes' demographic profile, oral hygiene practice and diet and information on energy drinks, mouth guards and chewing gums were elicited. A clinical examination was done according to WHO proforma 2013.

The reliability and reproducibility of data was carried out on a group of 20 subjects with a time interval of at least 30 minutes between the examinations. The Kappa co-efficient values $(0.80)$ showed substantial agreement on intra-examiner reliability. A pilot study consisting of 25 athletes was carried out to assess the prevalence of oral diseases and treatment needs and to assess the field condition of the study.
All the examinations were carried out by the investigator herself on the athletes. They were seated comfortably on an ordinary chair with back rest or on stools with the examiner standing behind or at the side of the chair. The examination was performed under natural day light. The subject was positioned so as to receive maximum natural illumination

Descriptive statistics was carried out. Mean standard deviation and chi square test were carried out. $\mathrm{p}<0.05$ was considered to be statistically significant.

\section{RESULTS}

A total of 350 athletes were recruited. Missing data resulted from participants not being available for data collection, incomplete data collection or a lack of transfer of data. Therefore a total of 300 athletes were finally included in the study.

The mean age of the athletes was $22.00 \pm 5.04$ year (range 10-35years) and $72.33 \%$ were men and $27.66 \%$ were women (Table 1). The majority of the athletes was from urban areas.

Table 1: Distribution of athletes by gender \& age

\begin{tabular}{|l|l|l|l|}
\hline Age group & Gender & Number & $\%$ \\
\hline \multirow{3}{*}{$10-15$} & Male & 14 & 4.6 \\
\cline { 2 - 4 } & Female & 6 & 2 \\
\hline \multirow{2}{*}{$26-20$} & Male & 70 & 23.3 \\
\cline { 2 - 4 } & Female & 35 & 11.67 \\
\hline \multirow{2}{*}{$26-30$} & Male & 62 & 20.67 \\
\cline { 2 - 4 } & Female & 31 & 10.33 \\
\hline \multirow{2}{*}{$31-35$} & Male & 54 & 18 \\
\cline { 2 - 4 } & Female & 4 & 1.3 \\
\hline Total & Male & 17 & 5.6 \\
\cline { 2 - 4 } & Female & 5 & 1.67 \\
\hline \multirow{2}{*}{} & & 300 & $100 \%$ \\
\hline
\end{tabular}

Around $70 \%$ of the athletes were having DMFT, out of them $68.66 \%$ had decayed teeth and only $12.66 \%$ had filled teeth (Graph 1).

More than half of the athletes $(67.66 \%)$ were free from the gingival bleeding condition (Graph 2).13\% of athletes were having pocket depth up to $4-5 \mathrm{~mm}$ and $3.3 \%$ athletes were having pocket more than $6 \mathrm{~mm}$.

$20.33 \%$ and $17.33 \%$ were having mild and moderate enamel fluorosis respectively (Graph 3). 


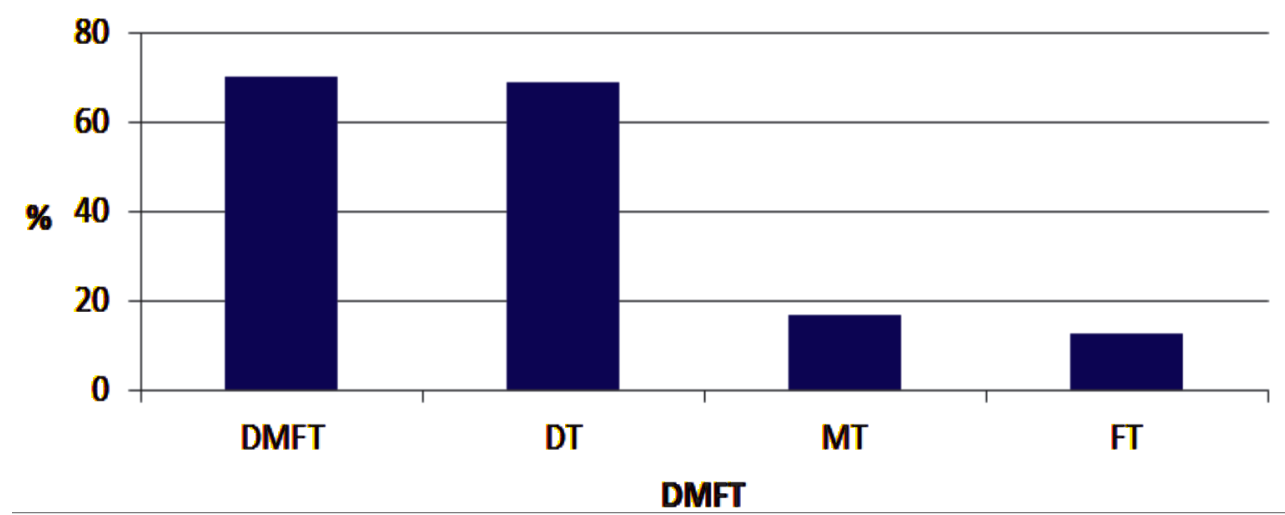

Graph 1: Number and percentage of athletes who have or have had caries of the permanent dentition (DMFT).

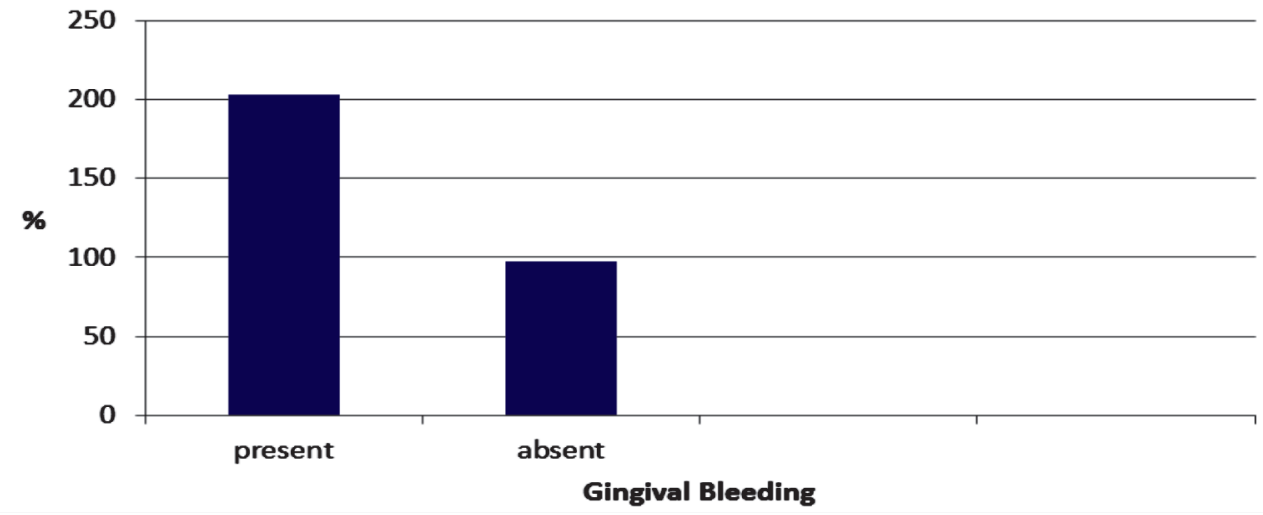

Graph 2: Number and percentage of athletes with gingival bleeding

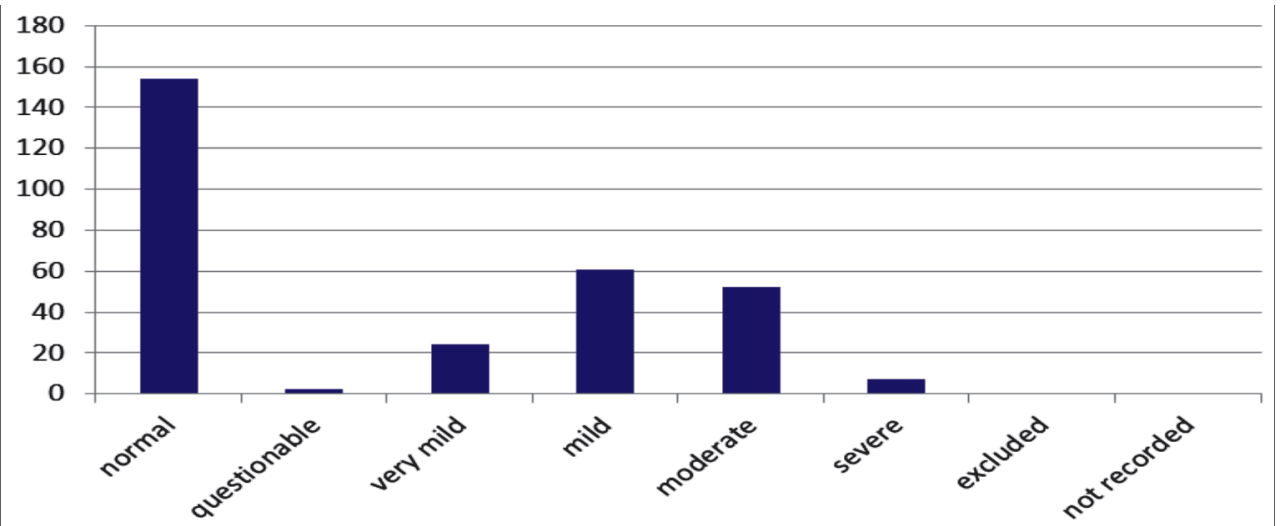

Graph 3: Number and percentage of subjects with enamel fluorosis, by level of severity. 
$9.3 \%$ of the athletes have enamel erosion (Table 2). $8.33 \% \& 8.66 \%$ of athletes were having treated injury and enamel fracture respectively (Table 3).

Table2: Number and percentage of athletes with dental erosion, by severity and percentage of teeth affected by dental erosion per athletes.

\begin{tabular}{|l|c|c|}
\hline \multicolumn{1}{|c|}{ Dental erosion } & Number & \% \\
\hline 0- No sign of erosion & 270 & 90 \\
\hline 1-Enamel lesion & 30 & 9.3 \\
\hline 2-Dentin lesion & 1 & 0.33 \\
\hline 3-Pulp involvement & 1 & 0.33 \\
\hline Total & 300 & 100 \\
\hline
\end{tabular}

Table 3: Number and percentage of athletes affected with traumatic injuries

\begin{tabular}{|l|c|c|}
\hline \multicolumn{1}{|c|}{ Dental trauma } & Number & $\mathbf{\%}$ \\
\hline 0-No sign of injury & 240 & 80 \\
\hline 1-Treated injury & 25 & 8.33 \\
\hline 2-Enamel fracture only & 26 & 8.66 \\
\hline 3-Enamel and dentin fracture & 8 & 2.66 \\
\hline 4-Pulp involvement & 1 & 0.33 \\
\hline 5-Missing teeth due to trauma & 0 & 0 \\
\hline 6-Other damage & 0 & 0 \\
\hline 9-Excluded tooth & 0 & 0 \\
\hline Total & 300 & 100 \\
\hline
\end{tabular}

$55.33 \%$ of athletes were consuming some drinks for dehydration during sports activity. About $50 \%$ of athletes were using chewing gum. About $20.66 \%$ of athletes were wearing mouth guard during playing. All athletes were using readymade mouth guards.
In this study there is no association between sports drinks and dental erosion and sports drink and dental caries (Graph 4 \& 5)

\section{DISCUSSION}

Oral health is important both for the well-being as well as successful elite sporting performance. Athletes represent a group of individuals who possesses specific risk factors of various dental diseases like dental caries, traumatic dental injuries, dental erosion and other related injuries.

The mean age of the athletes was $22.00 \pm 5.04$ year (range 10-35years). The majority of the athletes were from urban areas. Studies done by Needleman et $\mathrm{al}^{3}$, Aida Mulic et $\mathrm{al}^{4}$, Cosme Gay Escoda et $\mathrm{al}^{5}$ also had similar participant characteristics in terms of mean age (i.e. 25.7 years, 21 years, 21years respectively). Whereas in the study done by Leroy $\mathrm{R}^{6}$ in Belgium, the mean age of the participants was 33 years. In the present study, $72.33 \%$ of the participants were male and $27.66 \%$ were female. This is in contrast to the findings of Needleman et $\mathrm{al}^{3}$ and Aida Mulic et $\mathrm{al}^{4}$ who reported percentage of males as $57 \%$ and $35 \%$ respectively. This finding suggests that a higher number of females is involved in sports and athletics in other countries as compared to India.

The intense dietary and training pressures on athletes could put them at high risk of oral health problems for many reasons. The amount of energy that athletes need for training often means they have high-

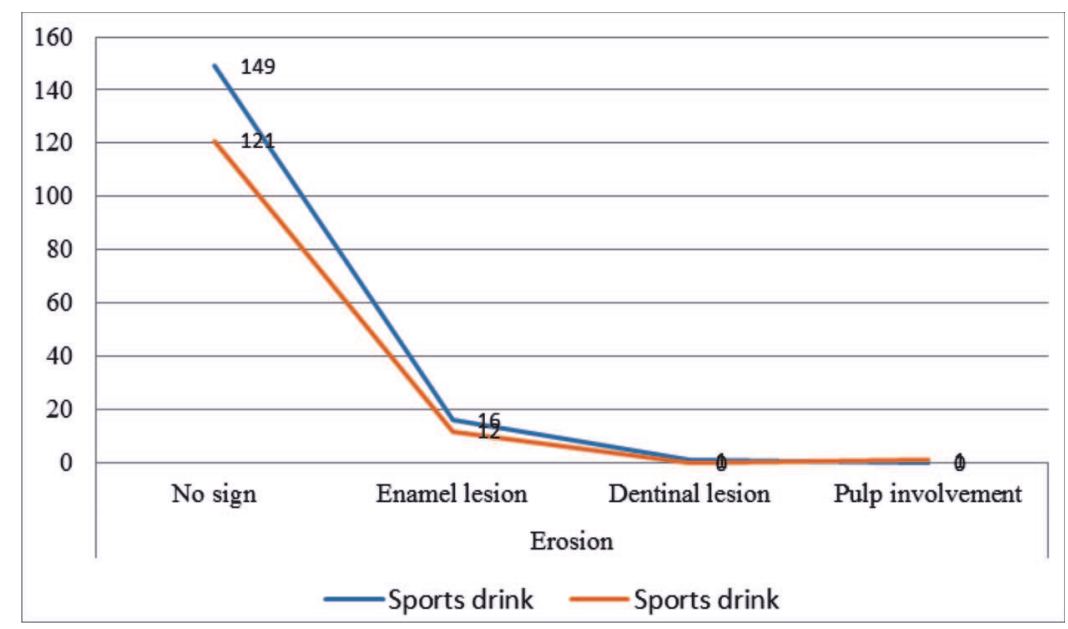

Graph 4: Association between sports drink and dental erosion 


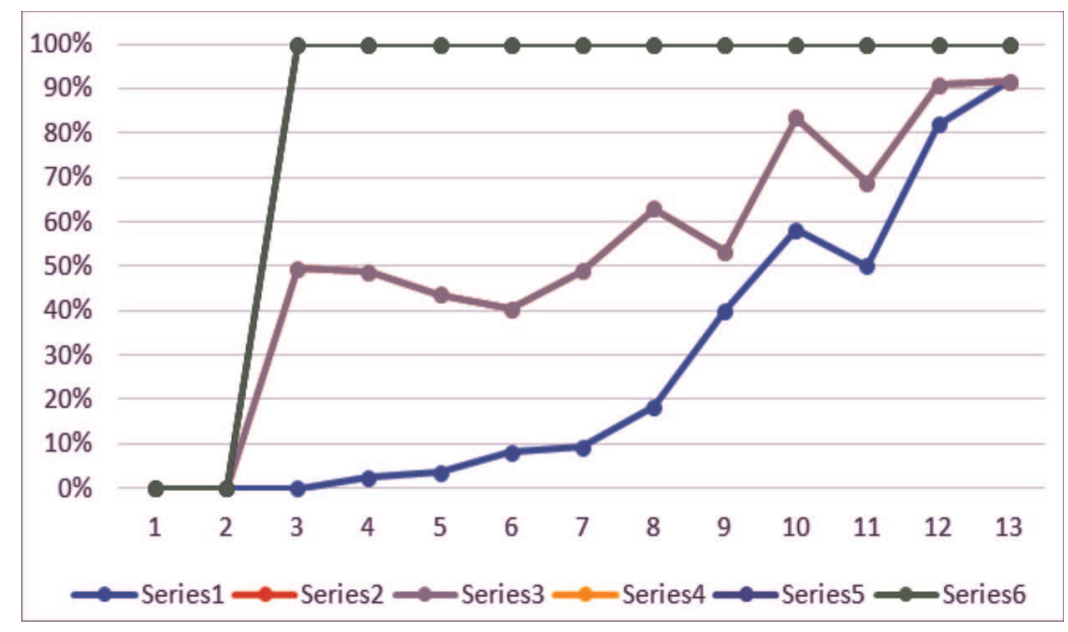

Graph 5: Association between sports drink and dental caries

carbohydrate diets and regularly use sugary, acidic energy drinks. Sports drinks are beverages whose stated purpose is to help athlete's electrolytes, replace water and energy after training or competition, though their efficacy is not known. Sports drinks provide many calories from sugars, to improve performance and endurance. Sugar-sweetened beverages have high levels of sugar and drinking these can significantly contribute to tooth decay and erosion. In the present study, there is no association with the consumption of sports drinks and dental erosion (Graph 4). Similar findings were in the study done by Mathew $\mathrm{T}$ et $\mathrm{al}^{7}$, Coombes JS ${ }^{1}$, Milosevic A et al ${ }^{8}$, Sirimaharaj V et al. ${ }^{9}$ A study done by the Aida Mulic et $\mathrm{al}^{4}$ stated that a higher prevalence of dental wear among young physical active individuals compared with a group of young adults who didn't exercise because of high consumption of acidic dietary components such as beverages citric fruits and sports drinks which causes increase the risk of erosive lesions.

The mean DMFT observed in the present study is 1.36, while Escoda GC et $\mathrm{al}^{5}$ in Barcelona found the DMFT of the players was very high i.e. 5.7. Ljungberg $\mathrm{G}$ et $\mathrm{al}^{10}$ in their study concluded that a soccer player on an elite level may have a somewhat higher risk of developing caries than non-players. Soler $\mathrm{BD}^{2}$ found caries risk and diseases levels have repeatedly been found to be high in athletes because of more carbohydrate intake and reduced salivary flow in the athletes. However, the relationship between the sports drinks and dental caries was not found to be statistically significant in our study (Graph 5). Similar findings were found in the studies done by Sorvari $\mathrm{R}$ et $\mathrm{al}^{11}$, Sorvari R et $\mathrm{al}^{12}$, Milosevic $\mathrm{A}^{8}$, Kelly MJ and Mclean $\mathrm{AN}^{8}$ and Borg A et al. ${ }^{13}$

More than 5 million teeth are avulsed each year; many during sports activities, resulting in nearly $\$ 500$ million spent on replacing these teeth yearly. In an issue of the Journal of the American Dental Association (JADA), it was reported that $13-39 \%$ of all dental injuries is sports-related, with $2-18 \%$ of the injuries related to the maxillofacial. ${ }^{14}$

Soft Tissue Injuries: The face is often the most exposed part of the body of athletic competition and frequent injuries to the soft tissues of the face, abrasions, contusions, and lacerations are common and should be evaluated to rule out fracture or other significant underlying injury. These usually occur to a bony prominence of the facial skeleton such as the brow, cheek, and chin. Lacerations of lips are also common. In the present study, the dental trauma is around 10\% (enamel fracture, enamel \& dentine fracture) while a study done by Marcos Britto Correa ${ }^{15}$ et al $70 \%$ of athletes developed disease because players by and large don't have sufficient knowledge of prevention of dental injury and mouth guards. Ferrari $\mathrm{CH}^{16}$ et al conducted a study which concluded that dental trauma suffered by $21.4 \%$ of soccer players in 
the study agrees with the mean $23 \%$ reported on soccer players.

With the many sports that children play, such as basketball, soccer, football, baseball, and all kinds of skating, it is recommended that dentists fabricate mouth guards for all patients especially children who participate in organized and disorganized sports. Stock mouth guards may be purchased from a sporting goods store, pharmacy, or a department store. Mouth guards are made of polyvinyl chloride, rubber, or a polyvinyl acetate copolymer. It offers good protection for interference in speaking and breathing. Dentistry should be working diligently to require mandatory use of mouth guards in all sports, which starts at the local and state level. Use of mouth guards during playing is $20.66 \%$ in the present study. Marcos Britto ${ }^{15}(21.6 \%)$ also found the similar result from their study.

The studies by Rajasthan Voluntary Health Association in 1994 have shown that the total numbers of villages having fluoride problems in Rajasthan is 2433 covering nearly 2.6 million population. Moreover, nearly 30,000 people are drinking water with a concentration of $10.0 \mathrm{mg} / \mathrm{ls}$ of fluoride. In our study, around $40 \%$ of athletes were having mild to moderate fluorosis.

The strength of this study included the number of athletes recruited $(n=300)$ and all the sports. The oral health improvement strategies will need to be developed and tested and these could include programs aimed at changing health behavior (including knowledge, awareness and oral health promoting activities), diet and the use and formulation of sports drinks and supplements.

\section{CONCLUSIONAND SUMMARY}

Sports dentistry - involves the prevention and treatment of or facial athletic injuries and related oral diseases, as well as the collection and dissemination of information on dental athletic injuries and the encouragement of research in the prevention of such injuries. The mean DMFT observed in the present study is 1.36 and $10 \%$ of the study participants had experienced dental trauma as a result of sports injury.
$32.33 \%$ athletes suffering from gingival bleeding. In the present study there was no association found between the sports drinks consumption and dental caries and erosion. About $50 \%$ of athletes were using chewing gums and $20.66 \%$ were using mouth guard during playing. The dental health of athletes is often poorer and may result in emergency problems that can compromise an athlete's performance.

\section{RECOMMENDATIONS}

- As oral health is an important element of overall health and well-being, health promotion and diseases prevention intervention are urgently required to optimize athletic performance. Mouth guard should be used before any activity so that we prevent dental trauma in the ground and should be mandatory and custom-made in all contact sports. Suggest athletes to use less numbers of energy drinks because it may cause dental erosion and decay. Sports committees must be developed. We should implement relevant preventive care programs. Opening the clinics during hours that work best for the athletes. Athletes should be educated on the potential harmful effects of the beverages like sports drink and techniques for minimizing this damage.

- Dental care should also be available on an emergency basis such as:

$\begin{array}{ll}\circ & \text { Treatment of broken or injured teeth } \\ \circ & \text { Fillings } \\ \circ & \text { Replacement of caps } \\ \circ & \text { Limited oral surgery's } \\ \circ & \text { Acute infections }\end{array}$

\section{REFERENCES}

1. Jefe S. Sports drinks and dental. American Journal of Dentistry 2005:18;101-4

2. SolerBadia D, Batchelor PA, Sheiham A. The prevalence of oral health problems in participants of the 1992 Olympic Games in Barcelona. Int Dent J 1994;444-48

3. Needleman I, Ashley P, Petrie A, Fortune F, Turner W, Jones J, Niggli J, Engebretsen L, Budgett R, Donos N, Clough T, Porter S. Oral health and impact on performance of athletes participating in the London 2012 Olympic Games: a crosssectional study. Br J Sports Med 2013;47(16):1054-8. 
4. Aida M, Anne T B, Dag S, Hanne S and Anne S B. Dental erosive wear and salivary flow rate in physically active young adults. Bmc oral health 2012;12:3-8

5. Gay-Escoda C, Vieira-Duarte-Pereira DM, Ardèvol J, Pruna R, Fernandez J, Valmaseda-Castellon E. Study of the effect of oral health on physical condition of professional soccer players of the Football Club Barcelona. Med Oral Pathol Oral Cir Bucal. 2011:16(3): e436-9.

6. Leroy R, Declerck D, marks L. The oral health status of special Olympics athletes in Belgium. Community dent health 2012;29(1):68-73.

7. Tanya M, Paul S C, John H. Relationship between sports drinks and dental erosion in 304 university athletes in Columbus, Ohio, USA. Caries res 2002;36:281-287.

8. Milosevic A, Kelly MJ, McLean AN. Sports supplement drinks and dental health in competitive swimmers and cyclists. Br Dent J 1997 Apr 26;182(8):303-8

9. Sirimaharaj V, Brearley Messer L, Morgan MV. Acidic diet and dental erosion among athletes. Aust Dent J. 2002;47(3):228-36.
10. Gutmann JL, Gutmann MS. Cause, incidence, and prevention of trauma to teeth. Dent Clin North Am 1995;39(1):1-13.

11. Sorvari R. Effects of various sport drink modifications on dental caries and erosion in rats with controlled eating and drinking pattern. Proc Finn Dent Soc 1989; 85: 13-20.

12. Sorvari R, Koskinen-Kainulainen M, Sorvari T, Luoma H. Effect of a sport drink mixture with and without addition of fluoride and magnesium on plaque formation, dental caries and general health of rats. Scand J Dent Res 1986;94:483-490.

13. Borg A, Birkhed D. Dental caries and related factors in a group of young Swedish athletes. Int J Sports Med 1987;8:234-235.

14. Olin. W.H. Dentistry and Sport- Meeting the Needs of Our Patients. JADA 1996:127:809-18.

15. Marcos Britto Correa. Survey on the occurrence of dental trauma and preventive strategies among Brazilian professional soccer players. JAppl Oral Sci 2010;18(6):572-6.

16. Ferrari $\mathrm{CH}$, Ferreria DE Mederious JM. Dental trauma and level of information: mouthguard use in different contact sports. Dent Traumatol 2002;18(3): 144-47. 